\title{
Adıyaman Halk Kültüründe Dua ve Beddualar (Alkışlar-Kargışlar)
}

\section{Prayers and Curses in Adiyaman Folk Culture (Acclamations and Imprecations)}

\author{
Yavuz UYSAL ${ }^{1}$
}

${ }^{1}$ Sorumlu yazar/Corresponding author Yavuz Uysal (Dr. Öğr. Üyesi)

Alanya Alaaddin Keykubat Üniversitesi, Eğitim Fakültesi, Alanya-Antalya, Türkiye

E-posta:yavuz.uysal@alanya.edu.tr

ORCID: 0000-0002-1383-2055

Başvuru/Submitted: 02.07.2019 Revizyon Talebi/Revision Requested: 13.07.2019

Son Revizyon/Last Revision Received: 17.07.2019

Kabul/Accepted: 26.09.2019

Online Yayın/Published Online: 14.11.2019

Atıf/Citation: Uysal, Yavuz. "Adıyaman Halk Kültüründe Dua ve Beddualar (AlkışlarKargışlar)." Türkiyat Mecmuası-Journal of Turkology 29, 2 (2019): 621-644.

https://doi.org/10.26650/iuturkiyat.646927 öz

Halk kültürü ürünleri, halkın aynası ve geleceğe aktarılan mirasıdır. Dua ve beddualar halk kültüründe kültür aktarımını sağlayan önemli sözlü anlatım türlerinden birisi olup insanların günlük hayat içerisinde farkında olarak ya da olmayarak en fazla kullandıkları kalıplaşmış sözlerdir. İnsanların hayatın akışı içerisinde karşılaştıkları olumlu davranışlar karşısında alkışta bulunmaları ya da dua etmeleri ne kadar doğal bir durum ise karşılaştıkları kötü hadiseler karşısında tepki olarak kargışta bulunmaları ya da beddua etmeleri de bir o kadar doğal bir durumdur. Türk toplumu içerisinde iyi davranışlar her zaman takdir edilir. Bu takdir halk kültüründe dualarla karşılık bulur. Ancak beddualar için bu durum tam tersi yönde algılanır ve beddua etmekten mümkün olduğunca uzak durulmaya çalışılır. Geçmişten günümüze, aktarılarak gelen alkış ve kargışlar kalıp sözlerdir. Bu yönüyle atasözü ve deyimlerle benzerlik gösterirler. Bu çalışmada, Adıyaman ili ve çevresinde halen canlı bir şekilde kullanılmakta olan dua ve beddua örnekleri incelenmiş ve diğer türler ile aralarındaki bağlar ortaya konulmuştur. Anahtar kelimeler: Adıyaman, Dua-Beddua, Alkış-Kargış, Halk kültürü, Kalıplaşmış sözler

\section{ABSTRACT}

Products of folk cultures are the mirror of the folk and are a heritage transferred to the future. Prayers and curses are significant verbal expressions which enable cultural transfer. They are also the most used stereotypical epithets used by people in their daily lives, either consciously or unconsciously. Just as people acclaim and pray for the positive situations they face, so it is natural that they imprecate when they are faced with negative situations. Positive attitudes are always admired and praised in Turkish society. This admiration is reflected by the prayers in folk culture. However, for curses, this situation is perceived quite differently. Therefore, curses are avoided whenever possible. Acclamations and imprecations, which are stereotypical epithets, have come from the past to present. In this aspect, they have many things in common with proverbs and idioms. In this paper, the types of prayers and curses used in daily life in Adıyaman city and its surrounding areas are studied along with their connections with other types. Keywords: Adıyaman, Prayer-Curse, Acclamation-Imprecation, Folk culture, Stereotype epithets 


\section{EXTENDED ABSTRACT}

Products of folk cultures are the mirror of the folk and are a heritage transferred to the future. Prayers and curses are significant verbal expressions which enable cultural transfer. They are also the most used stereotypical epithets used by people in their daily lives, either consciously or unconsciously. Just as people acclaim and pray for the positive situations they face, so it is natural that they imprecate when they are faced with negative situations. Positive attitudes are always admired and praised in Turkish society. This admiration is reflected by the prayers in folk culture. However, for curses, this situation is perceived quite differently. Therefore, curses are avoided whenever possible. Acclamations and imprecations, which are stereotypical epithets, have come from the past to present. In this aspect, they have many things in common with proverbs and idioms. Acclamations and imprecations are stereotypical epithets which are transferred from generation to generation and the harmony with which they are said and learned by heart are the result of common values of a society. These notions are so embedded in daily life that prayers and curses which are said by people living in different regions and as a result of a specific incident have many things in common. In respect of lexical meaning, prayer, which means "to call, to ask, to beg for help" and curse, which means "to damn, to make a bad wish" are literally the demands from Allah in case of being hopeless in bad situations.

Prayers and curses, the clearest examples of the fact that commitment to the religious values, wishes and desires can be carried out only through faith, are the stereotypical epithets that are used by people who commit themselves to Allah in relation to their own impotency. Prayers and curses which often refer to the following "Allah, holy book, prophet, thanksgiving, praise, good deed, sin, etc.", are the best examples of this commitment; in other words, to the people who have obstacles between them and cannot reach each other, 'may Allah unite you again!', to a person who is put in prison, 'may Allah rescue you!', to a person who does evil things, 'Allah damn you!', are said archetypally and it is obvious that many things are left to Allah. From all those things it is understood how impactful religion is in our society's worldview. In all these stereotypical epithets, the ones that start with Allah are most common. Turkish society generally avoids imprecations. This avoidance is also valid for vows too. To those who have a tendency to use imprecations and vows, they are told 'heaven forbid!', ' swear off!', ' do not persist!' and they are believed to tell many lies.

When someone speaks of a vow, the first expression group that comes to mind is proverbs and idioms. Acclamations and imprecations are closely associated with proverbs. The most common features of these types of sayings are: shortness and depth in expression, dignity in expression and being unchangeable in form. None of them can be considered independent of verbal speech. We should also use them where appropriate in the speech.

Another common feature of these sayings types is that their origins consist of word patterns dating back to time immemorial. While this situation anonymizes acclamations and 
imprecations, the fact that even the speakers do not know the meanings of some words becomes apparent. Swearings and "gülbenks" are the other cognate types grouped within acclamations and imprecations. Swearing may well be made up of rude and improper expressions but that doesn't prevent them from being rich in vocabulary and being used by people from every part, every cultural level and every age range of society. Moreover, it is very interesting that some of the words encountered in certain examples of swearing date back to Turks' pre-Islamic era. Another feature of swearing is that common and euphemized new words are used instead of words accepted as nasty or evil to produce new expressions. Many idioms which are said in Anatolia consist of such euphemized swearing. "Anasını bellemek" and " halt karıştırmak" are examples of this manner of swearing. Gülbenks are praying expressions which are said traditionally in Bektashi ceremonies or they are said by Bektashi dervishes while they are doing their daily chores.

We can always use acclamations and imprecations in daily life. These expressions not only meet people's need to transfer emotions and notions but also state feelings such as liking something, anger, and love. These stereotype epithets, which are not universal, can be different in different societies and people create them according to their own culture. They can be kept in mind, used in the appropriate place and time and also transferred to the next generations. Use of these stereotype epithets which consist of acclamations and imprecations can be different in every region, every city even in every village in the same language speaking societies.

90 acclamations and 220 imprecations are included in this study and we tried to sort these examples according to meaning and collocutor. The most significant feature of these expressions is that all of the acclamations are all demanded from or directed at Allah. Imprecations on the other hand are intensely based on the collocutor. In the grammatical context, we believe that Adiyaman's acclamations and imprecations will draw linguists' attention simply because they consist of many local dialect features. Since both acclamations and imprecations have examples concerning the whole society and are also used widely as idioms by everyone, they should be considered as universal sayings. 


\section{Giriş}

Dua ve beddualar üzerine çeşitli tanımlamalar ve araştırmalar yapılmıştır. İnsan hayatının bir parçasını oluşturan dua ve beddualar, birçok yazar ve araştırmacının ilgi alanına girmiş; böylelikle birçok farklı tanımlamaların da önü açılmıştır. Günümüzde dua ve beddua olarak adlandırılan kavram, Eski Türkçede farklı isimlerle karşılanmaktadır. Bu konuda kapsamlı çalışmaları bulunan Doğan Kaya, dua ve bedduayı tanımlamakla birlikte Eski Türkçede hangi kelimelerle karşılandığını şöyle ifade etmektedir:

Dua, iyi dilekleri ihtiva eden kalıplaşmış sözdür. Duaların en belirgin vasfi, teslimiyeti, inanmışlığ ve bir ümidi ihtiva etmeleridir. Genellikle görülen bir iyiliğe karşı söylenir. Karşıdaki kişi güzel ve hayırlı sözlerle kutlanır, hakkında iyi dileklerde bulunulur. Bugün yaygın kullanımıyla dua olarak bilinen bu söz, Eski Türkçede alkış kelimesiyle karşıllanmıştır. Alkış, alkamak hayır duada bulunmak, beğenmek, övmek fiilinden elde edilmiş bir isimdir. Türkçede bu kelimeye bağlı olarak; alkış alkamak, alkış almak, alkış çavuşu, alkış etmek, alkış tufanı, alkış tutmak, alkış vermek, alkışçı, alkışçılık, gibi sözler türetilmiştir.'

İlk olarak tarihi kaynaklarda Divan-1 Lugati’t Türk’te karşılaş1lan alkış sözcüğü, bu eserde, Dua etme, birinin iyiliklerini sayıp dökme, şeklinde tanımlanmıştır. Ayrıca büyü, efsun anlamındaki arkış sözcüğü de dikkat çekicidir. Bunlardan başka "alka-/arka-ş, alkışlamak, övmek”, “alkaş-, alkışlamak, alkışta yarış etmek” ve "karga-/karga-ş, kötülüğünü sayıp dökmek” sözleri de alkış sözüyle ilgili olarak Divan-1 Lugati’t Türk’te geçmektedir. Alkış ve kargışların sıklıkla kullanıldığı diğer önemli bir eser de Dede Korkut Kitabı'dır. ${ }^{2}$ Kitapta geçen hikâyelerin başında kullanılan alkışlar, Han'a övgülerle doluyken; sonunda söylenen alkışlar, Dede Korkut'un saadet ve hayır dileklerini ifade eder: "Devletsüz şerrinden Allah saklasun hanım sizi. Üç otuz on yaşunuz tolsun, Hak size yaman getürmesün, devletünüz payende olsun hanum hey. Karlu kara tağlarun yıkılmasun, ... ahir sonı aru imandan ayırmasun, amin diyenler didar görsün, ă̆ alnunda biş kelime du'a kılduk kabul olsun, Allah viren umudun üzilmesün, yığışdursun dürişdürsün günahunuzı adı görklü Muhammed Mustafa yüzi suyına bağışlasun hanım hey. "’3

Kısaca kötü dilek olarak nitelenebilecek beddua, Anadolu'nun muhtelif yörelerinde; ah, bedat, ilenç, inkisar, kargış, karış, lanet, gibi adlarla anılmaktadır. Çaresiz olan, acı çeken, kötülüğe maruz kalan bir insanın rahatlamak, teskin olmak gayesiyle söylediği, kötü düşünce ve dilekleri kapsayan beddualar, orijinal söylemleri ve ifadeyi güçlendiren anlamsal boyutuyla günlük hayatta en fazla kullanılan kalıplaşmış sözlerdendir. ${ }^{4}$ Eski Türkçede alkış ve kargış olarak nitelendirilen dua ve bedduaların mitolojik yönüne vurgu yapan Beydili, sözün gücünün etkisiyle tabiattaki varlıklara hükmedip; bu hükümleri doğal bir güçten dileme olarak dua ve

Doğan Kaya, Türk Halk Edebiyatı Terimleri Sözlüğü (Ankara: Akçă̆ Yayınları, 2007), 261.

Ali Duymaz, "Sihir Şiirlerinin Bir Türü Olarak Alkışlar”, Milli Folklor 45 (2012), 15-16.

Muharrem Ergin, Dede Korkut Kitabı (Ankara: Türk Dil Kurumu Yayınları, 2004), 74-115.

Kaya, Türk Halk Edebiyatı Terimleri Sözlüğ̈̈, 146-147. 
bedduaların inanç boyutuna değinmiş ve bu kavramları mitolojik düşüncenin ilk evrelerine dayandırmıştır. ${ }^{5}$ Alkış ve kargış ifadeleri aslen Türkçe olsa da bu ifadeler Türklerin İslamiyete girmesinden sonra değişikliğe uğramış; alkış yerine dua, kargış yerine de beddua terimleri kullanılmaya başlanmıştır.

Alkış ve kargışlar, hem söylenişlerindeki ahenk hem de kolay ezberde kalmaları yönüyle nesilden nesle aktarılan ve toplumun ortak değer yargılarının bir sonucu olarak ortaya çıkan kalıp sözlerdir. Günlük hayat içerisinde bu kavramlar o kadar toplumun içerisine yerleşmiştir ki herhangi bir olay karşısında farklı coğrafyalarda yaşayan insanların dudaklarından dökülen dua ve beddualar birbirleriyle oldukça fazla benzerlik göstermektedir. ${ }^{6}$ Kelime anlamı itibariyle; "seslenmek, istemek, yardım dilenmek" manalarına gelen dua ile "lanetlemek, kötü dilekte bulunmak" anlamlarına gelen beddua, kulun acizliği karşısında Allah’tan istenmektedir. Dua ve bedduayı, Tanrı'ya yapılan bir sesleniş olarak ifade eden Şükrü Elçin, duayı "İnsanın kendisi ile içinde yaşadığı cemiyetin maddi refah ve manevi saadetinde yardım ve merhametini istemek üzere Tanrı'ya yaptığı bir hitap, bir sesleniştir" şeklinde yorumlarken; bedduayı, duanın tam zıddı olan menfi sözler olarak ifade etmiştir. ${ }^{7}$ Dini değerlere bağlılığın, istek ve temennilerin sadece inanç ile gerçekleştirilebileceğinin günlük hayattaki en bariz örnekleri olan dua ve beddualar, insanların acizlikleri karşısında kendilerini Allah'a teslim ettikleri kalıp sözlerdir. Allah, kitap, peygamber, şükür, hamd, sevap, günah vb. ifadelere s1klıkla başvurulan dua ve beddualar, bu teslimiyetin en güzel örneğidir. Söz gelişi, aralarına engeller giren kavuşamayan insanlara Allah kavuştursun! Ceza evine giren bir mahkûma Allah kurtarsın! bir kötülük yapana Allah belanı versin! gibi sözler söylenerek birçok işin Allah’a havale edildiği görülmektedir. Tüm bunlardan da Türk halkının dünya görüşünde dinin ne kadar etkili olduğu anlaşılmaktadır. Bu sebeple tüm kalıp sözler içinde, Allah kelimesi ile başlayanlar en geniş yere sahip olanlardır. ${ }^{8}$ Türk toplumu genelde kargıştan sakınır. Bu sakınış ant için de geçerlidir. Ağzı kargışa ve Ant'a alışık olanlara Aman ă̆zını hayra aç, aman tövbe de, aman pek üsteleme... denir ve çok ant içenlerin çok yalan söylediklerine inanılır. ${ }^{9}$

Ant denilince ilk akla gelen anlatım gurubu, Atasözleri ve deyimlerdir. Alkış ve kargışlar, atasözlerinden ayrı düşünülemez. Bu üç türün ortak özellikleri, anlatımlarındaki kısalık ve yoğunluk, anlatımlarındaki ağırbaşlılık ve üzerlerinde herhangi bir değişikliğe müsaade etmemeleridir. Her üçü de sözlü konuşmadan bağımsız düşünülemez ve söz içerisinde gerektiği yerde kullanılmalıdır. Sözlerini atasözleri ile destekleyen bir konuşmacı ne derece etkili bir konuşma yapıyorsa, alkış ve kargışları da yerli yerinde kullanmayı bilen konuşmacılar, o derece

5 Celal Beydili, Türk Mitolojisi Ansiklopedik Sözlük, çev. Eren Ercan (Ankara: Yurt Yayınları, 2005), 53-54.

6 Öykü Terzioğlu, "Alkış ve Kargışların Sözlü Kültürdeki Yerleşik Kodların Aktarımını ve Yeniden Üretimini Kolaylaştıran Biçimsel Özellikleri”, Milli Folklor 75 (2007), 34-37.

7 Şükrü Elçin, Halk Edebiyatına Giriş (Ankara: Akçağ Yayınları, 2004), 662.

8 Serdar Bulut, “Anadolu Ağızlarında Dini İnançları Yansıtan Kalıp Sözler”, The Journal Of Academic Social Science Studies (JASSS) 6/1 (2013), 437.

9 L. Sami Akalın, Türk Dilek Sözlerinden Alkışlar Kargışlar (Ankara: Kültür Bakanlığı Halk Kültürünü Araştırma Dairesi Yayınları, 1990), 51. 
etkili sunum yaparlar. Toplum içerisinde alkışlar hak eden insanlara sunulurken; kargıştan da bir o kadar kaçınılır. Bu üç türün diğer bir ortak özelliği de kökenlerinin çok eskilere dayanan söz kalıplarından oluşmuş olmasıdır. Bu durum, alkış ve kargışları anonimleştirirken söyleyenlerinin bile bazı kelimelerin anlamlarını bilmediği gerçeğini de ortaya çıkarmaktadır. ${ }^{10}$ Alkış ve kargışlarla akraba niteliğinde olan diğer türler arasında küfürler ve gülbenkler gösterilebilir. Küfürlerin, içeriğinde bulunan kaba ve çirkin söyleyişler, onların toplumun her kesiminden, her yaşta ve her kültür seviyesinde insanlar tarafindan kullanıldığı ve zengin bir söz varlığına sahip oldukları gerçeğini ortadan kaldırmaz. Hatta bazı küfürlerde karşılaşılan kelimelerin Türklerin İslamiyet öncesine kadar uzanan bir geçmişi olması dikkat çekicidir. Küfürlerin söylenişindeki bir diğer özellik de ayıp ya da günah sayılan sözlerin yerine, alışılmış ya da anlamca hafifletilmiş yeni kelimeler kullanılarak yeni sözler üretmek şeklinde olmuştur ki Anadolu'da söylenen birçok halk deyimi, anlamca hafifletilmiş bu küfürlerden meydana gelmiştir. Anasını bellemek, halt karıştırmak gibi ifadeler bu söyleyişlere örnektir. Gülbenkler ise Bektaşi tarikatının belirli törenlerinde ya da Bektaşi dervişlerinin türlü işlerini yaparken söylenmesi gelenek haline dönüşen dua sözleridir. ${ }^{11}$ Gülbankler aynı zamanda savaşlarda ve dinsel törenlerde topluca okunan düzenli dua sözleri anlamına da gelir ve ezan için Gülbenk-l Muhammedi terimi kullanılır. ${ }^{12}$ Yine Salavat ya da Gülbenk olarak ifade edilen pehlivan duaları da bir nevi alkış olarak değerlendirilebilir. Nitekim gerek Boratav, gerekse Elçin, pehlivan dualarını alkışlar içerisinde değerlendirmişlerdir. ${ }^{13}$ Alkış ve kargışların nasihatler ile aralarındaki bağa dikkat çeken Çobanoğlu ise nasihatlerin de hiyerarşik bir yapısının olduğundan ve yaşça küçük birinin büyük birine nasihat edemeyeceğinden bahsederken, nasihatlerin oluşumunda mutlaka geçmişte yaşanmış bir tecrübenin olması gerektiği üzerinde durmuştur. Nasihatlerle alkış ve kargışların bir arada kullanılmasının bu türlerin geniş halk kitleleri tarafından aynı şekilde algılanmasına sebep olduğuna değinen Çobanoğlu'nun sunmuş olduğu şu örnek, bu algının sebebini de ortaya koymaktadır:

\begin{abstract}
Havva teyzenin annesi gelin olmuş. Aynı sene seferberlik olmuş, kocası askere gitmiş ve şehit olmuş. Gelin kaynana beraber oturuyorlarmış. Köyden bir adam geline göz koymuş; ona seni alacam deyip duruyormuş. Eskiden köyde suları omuzlukla taşılarmış. Gelin sudan gelirken adam kadının peşinden eve kadar gelmiş. Kayınvalidesi ocă̆ın önünde oturuyormuş; adam da arkasından gelip geline sarılıp öpmüş. Kayınvalidesi geline demiş ki - Kızım bu adam senin adını çıkartacak, senin iyi olduğunu biliyorum; ama sen bu adamla evlen! Gelini bunu kabul etmemiş. Kadın da bunun üzerine adama beddua etmiş: "İnşallah benim oğlum gibi sen de kurşunlara gelesin!" demiş ve adam da vurularak ölmüş.
\end{abstract}

10 Pertev Naili Boratav, Türk Halk Bilimi I-100 Soruda Türk Halk Edebiyatı (İstanbul: Gerçek Yayınevi, 1995), 118.

11 Boratav, Türk Halk Bilimi I-100 Soruda Türk Halk Edebiyatı, 128-131.

12 Akalın, Türk Dilek Sözlerinden Alkışlar Kargışlar, 45.

13 Duymaz, "Sihir Şiirlerinin Bir Türü Olarak Alkışlar", 20. 
Örnek olayda, kocası savaşta şehit olmuş bir geline sarkıntılık yapan bir adamın varlığı ve onu gözünün önünde sarılarak öpmesi üzerine birlikte yaşadığı kaynanası gelinine, namusunu korumak için bu adamla evlenmesini nasihat etmektedir. Ancak gelin kaynanasının nasihatini kabul etmez ve adamla evlenmez. Bunun üzerine başka çaresi olmadığı görülen kaynana, adama, Sen de benim oğlum gibi kurşunlara gelesin! diye kargışta bulunur. Bundan bir zaman sonra adam vurularak öldürülür. Nasihatin ve bedduanın iç içe geçtiği bu örnek olay, iki tür arasındaki ilişkiyi gözler önüne sermektedir. ${ }^{14}$

Alkış ve kargışlar, günlük hayat içerisinde her durum için başvurulabilecek sözlerdir. Bu sözler insanların duygu ve düşüncelerini karşı tarafa aktarma ihtiyacını giderdiği gibi aynı zamanda sevgisini, beğenisini ya da kızgınlığını da ifade ettiği sözlerdir. ${ }^{15}$ Evrensel olmayıp, tolumdan topluma değişen ve insanların kendi kültürüne özgü oluşturduğu bu kalıp sözler, hafızalarda saklanıp, yeri ve zamanı gelince kullanılan ve gelecek kuşaklara aktarılan toplumsal mirastır. Alkış ve kargışların da içinde bulunduğu kalıp sözlerin kullanımı, aynı dili konuşan toplumlarda bile her bölgede, her ilde, hatta her köyde birbirinden farklı şekillerde ortaya çıkabilir. ${ }^{16}$ Boratav, alkış ve kargışları, iki ayrı sınıflama ile ele almış ve günlük hayat içerisinde fazlaca kullanılan ve konuşmayı renklendiren kısa kalıp ifadeler ile içeriğinde fazlaca derin anlamlar üstlenen ve özenilerek seçilmiş küçük sanat yapıtları olarak değerlendirdiği sözleri birbirinden ayırmıştır. Bu bağlamda, birinci sınıfta yer alan alkış ve kargışları halk edebiyatı türü olarak değerlendirmenin yersiz olacağına vurgu yaparak, ikinci sınıfta ele aldığı kalıp ifadelerin anlam yüküne dikkati çekmiştir. ${ }^{17}$

$\mathrm{Bu}$ çerçevede Adıyaman yöresinden derlenmiş olan alkış ve kargışlar, kendi içinde yüklendikleri anlamlara göre sınıflandırılmıştır.

\section{Adıyaman Halk Kültürüne Ait Dua ve Beddua Örnekleri}

\subsection{Dua (Alkış)}

Geniş bir şekilde farklı tanımlamaları verilen dualar, insanların kendilerine yapılan bir iyiliğin karşısında, muhataplarına karşı yöneltmiş oldukları teşekkür sözleridir. Bu haliyle dualar her zaman ve her şartta yapılan kişinin iyiliğini ve esenliğini dilemektedir. Dua ya da alkış olarak ifade edilen bu kavram, karşı tarafa yöneltilen iyi dileklerin yanında anlatımı etkili kılmak ve kelimelere anlam yüklemek maksadıyla da kullanılmaktadır. Türkiye coğrafyasının hemen hemen her bölgesinde aynı şekilde ve aynı anlamda kullanılan duaların yanında, şekil ve anlam bakımından farklılıklar göstererek yöresel söyleyişlerin de etkisiyle farklı kalıplarda karşılaşılan dua örneklerini de görmek mümkündür. Bu durum, olayları değerlendiren toplumsal düşüncenin

14 Özkul Çobanoğlu ve Sacide Çobanoğlu, "Türk Halk Kültüründe Konuşmalık Türler Bağlamında Sözel Nasihatler, Dua ve Beddualar”, Avrasya Uluslararası Araştırmalar Dergisi 4/7 (2015), 9.

15 Meriç Harmancı, "Dede Korkut Hikâyelerindeki Alkış ve Kargışlara İşlevsel Bir Yaklaşım”, Kocaeli Üniversitesi Sosyal Bilimler Enstitüsü Dergisi 23 (2012), 14.

16 Serdar Bulut, "Türkiye Türkçesi Ağızları İle Kıbrıs Türk Ağızlarında Ortak Kullanılan Kalıp Sözlerden HayırDualar ve Beddualar”, Akademik Sosyal Araştırmalar Dergisi (ASOS JOURNAL) 4/24 (2016), 300.

17 Boratav, Türk Halk Bilimi I-100 Soruda Türk Halk Edebiyatı, 125-128. 
bölgeden bölgeye farklılık göstermesinden kaynaklanmaktadır. Adıyaman' da insanlar, hemen hemen bütün bölgelerde olduğu gibi kendilerine, yakınlarına, hastalara, askerlere, çocuklara, yaşlilara, zor durumda olanlara, kimsesizlere ve dua bekleyen herkese dua etmekten kaçınmazlar. Çünkü toplumsal bir algı olarak karşılık beklemeden ve samimi duygularla yapılan duaların yerini bulacağı ve kabul olacağı inancı, Adıyaman halkının tamamında hâkimdir. Özellikle, Allah dostu diye nitelendirilen velilerin, ermişlerin ve temiz kalpli insanların yapmış oldukları duaların mutlaka kabul edileceği inancı, insanları dua ekseninde iyilik yapmaya ve temiz kalpli olmaya yönlendirdiği de bir gerçektir. Duanın kabul olması ile dua edilirken içinde bulunulan samimiyet ve teslimiyet arasında sıkı bir bağ vardır. Dua edildikten sonra ya da herhangi bir olay karşısında tavır sözü olarak söylenen, Allah bilir! ya da yapılan bir duanın arkasından söylenen Inşallah! sözü, inançlı veya inançsız herkesin dudaklarından dökülen ve teslimiyeti ortaya koyan dua sözleridir. Aynı zamanda insanların zor durumda kaldıklarında ve çaresizlik içerisinde beklerken tek çare aradıkları sözcükler yine dua sözleridir. Bu bağlamda Adıyaman ili ve çevresinden derlenen dua örneklerini dört alt başlık altında sıralamak mümkündür.

\subsubsection{Kişinin Kendisi İçin Ettiği Dualar}

- Allah'ım beni cennetine al.

- Allah'ım beni şeytanın şerrinden koru.

- Allah'ım bana hayırlı kismetler ver.

- Allah'ım bana can sağlığı ver.

- Allah'ım günahlarımı affet.

- Allah'1m beni koru.

- Allah'ım bana hayırlı işler, bol kazançlar ver.

- Allah'ım herkesin muradını ver, benimkini de ver.

- Allah'ım emeğimi boşa götürme.

- Allah'ım bana helal kazançlar ver.

- Allah'1m beni darda koyma.

- Allah'ım bana yardım et.

- Allah'ım işlerimi rast götür.

- Allah'ım beni kimseye muhtaç etme.

- Allah'ım beni doğru yoldan şaşırtma.

- Allah'rm beni elden ayaktan, gözden etme.

- Allah'ım beni şirin akıldan etme.

- Allah'ım bana sağlik-sıhhat ver.

- Allah'ım beni feraha çıkar.

- Allah'ım beni pis eyleme, intizar eyleme.

- Allah'1m beni boynu bükük eyleme.

- Allah'ım beni duvar önlerinde koma. 
- Allah'ım bana hayırlı evlatlar nasip eyle.

- Allah'ım iki iyiliğin birisini ver (İyilikten kasıt yaşam ve ölüm).

\subsubsection{Kişinin Sevdikleri ve Yakınları İçin Ettiği Dualar}

- Allah muradına göre versin.

- Allah muradinı yapsin.

- Allah gönlüne göre versin.

- Seni sana ve Allah'a teslim ettim.

- Allah seni korusun.

- Geçmişlerinin mekânı cennet olsun.

- Geçmişlerine rahmet.

- Kesene bereket.

- Hayırlı işler, bol kazançlar.

- Allah sana sabir versin.

- Allah'a 1smarladik.

- Allah seni kaza ve belalardan korusun.

- Allah'a emanet ol.

- Allah emeğini boşa götürmesin.

- Allah seni zorda koymasin.

- Allah yardimcin olsun.

- Allah yardım etsin.

- Allah zihin açıklığı versin.

- Allah seni, Allah dostlarının yüzü suyu hürmetine muhafaza etsin.

- Kazası-belasız evine dönesin.

- Allah seni ele muhtaç etmesin.

- Allah senden razı olsun.

- Allah seni doğru yoldan şaşırtmasın.

- Allah Müslümanları zalimlerin elinden kurtarsın.

- Allah Muhammed'in dinini zelül etmesin, zorda birakmasin.

- Allah seni başka kapılara muhtaç etmesin.

- Allah seni elden-ayaktan düşürmesin.

- Allah seni imandan etmesin.

- Allah sonunu güzel etsin.

- Allah sana zeval vermesin.

- Allah senin bahtını açık etsin.

- Allah sana hayırlı kapılar açsın.

- Allah seni Muhammed'in dininden ayırmasin.

- Ne dua ediyorsan Allah onu kabul etsin.

- Allah-Peygamber senden razı olsun. 
- Allah işini-gücünü rast getirsin.

- Allah herkesi yerinde ayık etsin.

- Hoca-Hızır yoldaşın olsun.

- Allah seni incitmesin.

- Allah ciğerini yandırmasın.

- Bir kapıda kalan, kapı kapı dolanmayan.

- Allah işini doğru etsin.

- Allah seni duvar önünde koymasin.

- Allah sana din-iman versin.

- Allah hayırlı-uğurlu etsin.

- Allah sana ak1l-fikir versin.

- Allah sana hayırlı evlat versin.

- Allah niyetlerini kabul etsin.

- Allah seni yormasin.

- Allah seni iyilerle karşılaştırsın.

- Allah seni el altında bırakmasın.

- Allah sana kabir azabı çektirmesin.

- Allah hayrinı kabul etsin.

- Allah ağzının tadını bozmasın.

- Allah seni dile düşürmesin.

- Allah sefil kazalardan korusun.

- Allah yar ve yardimcin olsun.

- Kızım, bahtın da olsun tahtın da olsun.

- Ocağın şenlensin, görkünü gören.

- Birin bin ola.

- Tuttuğun altın ola.

- Bir elin yağda bir elin balda ola.

- Hoca Hizır yoldaşın ola.

- Dilin tatlı ağzın ballı ola.

- Duvağınla, gelinliğinle giden.

- Koç yiğitler doğuran.

- Doğduğunda biz güldük, öldügünde sen gülen.

- Oğlum, eşiğin şen ola.

- Bir yastıkta kocayasınız.

- Vatana millete hayırli olan.

- Evlatlarından hayır gören.

- Malından mülkünden hayır gören.

- Malınla, evladinla yorulmayan. 


\subsubsection{Kişinin Hastalara Ettiği Dualar}

- Allah sana sağlik-sihhat versin.

- Geçmiş olsun.

- Allah sana merhamet etsin.

- Allah sana şifa versin.

- Allah sana rahatlik versin.

\subsubsection{Kişinin Allah'a Ettiği Dualar}

- Allah'ım sana şükürler olsun.

- Allah'1m sana hamdolsun.

- Çok şükür.

- Bin şükür.

- Elhamdülillah.

- Allah'ım keremine, rahmetine, verdiklerine şükürler olsun.

- Allah Kuran, İman ve can sağlığı versin.

\subsection{Beddua (Kargış)}

Beddua, herhangi bir kızgınlık halinde insanların dilinden dökülen kötü dileklerdir ve yapılan tanımlamaların hemen hepsinde kargış ifadesiyle eşdeğer kabul edilmiştir. ${ }^{18}$ Alkışlarda olduğu gibi kargışlarda da dile getirilen istek ve temennilerin kabul olup olmayacağ 1 Allah'ın takdirine bırakılmıştır. Akalın kargışlar, beddualar ve ilençleri ayrı başlıklar altında değerlendirmiş ve hepsinin birbirinden farklı olduğunu küçük nüanslarla açıklamaya çalışmıştır. Buna göre kargışlar ile beddualar arasında dini inanç bağlamında farklılıklar vardır. Dua ve beddualarda istenilen ya da dilenilen istek ve temennilerin muhatabı Allah’tır. Alkış ve kargışlarda ise muhatap, iyiliği ya da kötülüğü temenni edilen kişidir. İlenç kavramında ise süreklilik ve daha uzun bir zaman dilimine yayılmış temenniler yer almaktadır. ${ }^{19}$ Konuya anlam ölçeğinden bakılacak olursa, toplum nezdinde beddua etmek, ilenmek ya da kargışta bulunmak ifadeleri arasında herhangi bir fark bulunmamaktadır. Yani Akalın'ın ifade etmiş olduğu küçük farklılıklar, toplum nezdinde ortak olarak algılanmakta ve kavramlar arasındaki farklılık, insanları kavramsal bir tanımlama meselesine sürüklememektedir. Hele ki yapılan çalışmaların, bu çalışmada olduğu gibi yöresel derlemelerle mukayesesi söz konusu olduğunda, bu çeşitlenme tek başlık altında toplanmakta ve sadece beddua kavramı üzerinde birliktelik sağlanmaktadır. Kargış ifadesi daha çok Türkiye coğrafyasının sınırları dışında söylenegelen bir kavram olarak algılanmaktadır.

Çalışma sahasını oluşturan Adıyaman ili ve çevresinde, beddua ve ilenme kavramı sıklıkla kullanılırken; alkış kavramına neredeyse hiç rastlanmamıştır. Beddualar genellikle, bir kişinin haksızlığa uğraması, canının yanması ve çaresizlik içerisindeyken; bütün bunlara sebep olan

18 Serpil Ersöz, "Türkiye Türkçesi Doğu Grubu Ağıllarında Bedduaların İşlevleri”, Türk Dünyası İncelemeleri Dergisi XIV/2 (2014), 30.

19 Akalın, Türk Dilek Sözlerinden Alkışlar Kargışlar, 49-52. 
kişilere karşı söylediği kötü temenniler, olarak algılanmaktadır. Bu kişi beddua eden kişinin yakın bir akrabası ya da arkadaşı da olabileceği gibi yeni tanıştığı ya da hiç tanımadığı bir kişi de olabilir. Haksızlığa uğrayan, kalbi temiz ve masum olan insanların, ermişlerin, ulemaların ve üzerinde farz namazı borcu bulunmayan insanların, yapmış oldukları bedduaların tutacağına inanılmaktadır. Aile içerisinde, babanın yaptığı bedduanın kabul olacağı; annenin bedduasının önüne ise anne sütünün engel olacağı ve dolaysıyla bedduasının tutmayacağı inancı hâkimdir. Çünkü babanın gönülden beddua edebileceği; ancak hiçbir annenin kendi doğurmuş olduğu evladına gönülden kötülük dileyemeyeceği inancı bulunmaktadır. Konu ile alakalı olarak kaynak şahıslardan Zahide Hanımın anlatmış olduğu hadise konuyu tam olarak özetlemektedir:

Ben sevdiğim insanla evlendim fakat babam bu evliliğe karşıydı. Ben her şeye rağmen evlendim ve babam bana 'Sen olan hayır görmeyen!' şeklinde beddua etti. Evlendikten sonra çeşitli sağlık problemleri yaşadım ve astım hastalığına yakalandım. Birçok doktora gitmeme ve çeşitli ilaçlar kullanmama rağmen bir türlü iyileşemedim. Aradan biraz zaman geçtikten sonra babamla aramız düzeldi ve bana “Sen olan hayır gören!” dedi. O gün bugündür rahatsızlığımdan tamamen kurtuldum ve iyileştim. Baba bedduası her zaman tutar, ben buna inaniyorum!

Bu örnek olayda Zahide Hanım'ın yaşadığı hadise, aslında babanın sadece bedduasının değil, duasının da evlat üzerinde oldukça etkili olabileceğini göstermektedir. Adıyaman'da beddualar genellikle kadınlar tarafindan yapılmaktadır; erkekler ise beddua etmezler ve çaresiz kaldıklarında daha çok küfre başvururlar. Beddualar, günlük hayat içerisinde çok sık kullanılmasına rağmen beddua etmek hoş bir davranış olmadığ için ve haksız yere yapılan bedduanın, tekrar sahibine döneceği inancından kaynaklı olarak insanlar beddua etmekten çekinirler. Hatta beddua etmenin dinen hoş karşılanmamasından dolayı yapılan haksızlıkları Allah'a havale etmenin en doğru davranış olacağının da altı çizilmektedir.

Halk içerisinde belirli bedduaların sıklıkla kullanıldığına dikkat çeken Kaya, çevrenin durumu, olayların önemi ve insanların psikolojik yapılarına bağlı olarak farklı beddua örneklerine de rastlanabileceğini belirtmiş ve bedduaları yedi alt başlıkta sınıflandırmıştır: "1. İnsan için söylenen beddualar, 2. Beldeler için söylenen beddualar, 3. Yapılar için söylenen beddualar, 4. Hayvanlara söylenen beddualar, 5. Tabiat parçaları (ağaç, dağ, ırmak...) için söylenen beddualar, 6. Feleğe söylenen beddualar, 7. Gurbete söylenen beddualar". ${ }^{20}$ Konu ile alakalı olarak, Emine Gürsoy Naskali Hanımefendi'nin editörlüğünde yakın tarihte çıkmış olan Lanet Kitabı'nda Arzu Çiftçioğlu, Bedduaların Anlam Açısından Incelenmesi başlıklı yazısıyla, bedduaları on altı alt başlıkta ele almış; anlamca yakınlıklarına ve benzerliklerine göre tasnif etmiştir:

1. İnsana atıf yapan beddualar, 2. Aile ve aile hayatına atıf yapan beddualar, 3. Cinselliğe atıf yapan beddualar, 4. Deli ve delilik kavramına atıf yapan beddualar, 5. Yeme içme kavramına atıf yapan beddualar, 6. Giyinmek ve giyim kavramına atıf yapan beddualar, 7. Ev kavramına

20 Doğan Kaya, "Dualar ve Beddualar”, Türklük Bilimi Araştırmaları Dergisi 4 (1997), 99-121. 
atıf yapan beddualar, 8. İnançlara atıf yapan beddualar, 9. Hak ve hüküm kavramlarına atıf yapan beddualar, 10. Maddiyatla ilgili kavramlara atıf yapan beddualar, 11. Yol ve yolculuk kavramlarına atıf yapan beddualar, 12. Müzik aletlerine atıf yapan beddualar, 13. Bitki ve hayvanlara atıf yapan beddualar, 14. Gök, hava, iklim kavramlarına atıf yapan beddualar, 15. Dünya, yeryüzü ve yer bölümlerine atıf yapan beddualar, 16. Beddua kavramına atıf yapan beddualar. ${ }^{21}$

Bu tasnif, Kaya'nın yapmış olduğu tasnif çalışmasının genişletilmesiyle oluşmuş ve içerik olarak birbirini kapsayan bir tasnifleme olmuştur. Konuya Hedef Kişi ve Bağlam açısından yaklaşan Ersöz ise beddualarda hedef kişi olarak, bedduaya maruz kalan kişiyi işaret etmiş ve bağlam ölçeğinde bu kişinin ya kendisi ya da başka bir kişi olabileceğinin altını çizmiştir. Bunlara ek olarak da hedef kişinin bunlardan hiçbiri olamayacağını ve herhangi bir kızgınlık halinde konuşmacının ağzından o anda dökülüveren beddua sözleri olarak değerlendirmiş ve hedef kişi olarak karşıda bir kişinin olmadığı durumlarda söylenen beddua örneklerine yer vermiştir:

\subsection{Hedef Kişi, Konuşucunun Karşısındaki Kişi ya da Kişilerdir. \\ 1.1.1. Önemsizdir ya da Sevilmeyen Biridir. \\ 1.1.2. Önemlidir ya da Sevilen Biridir. \\ 1.2. Hedef Kişi, Konuşucunun Kendisidir. \\ 1.2.1. Yemin Etmek. \\ 1.2.2. Haylflanmak. \\ 1.3. Hedef Kişi, Hiç Kimsedir.22}

Verilen bu tasnif çalışmaları, farklı araştırmacılar tarafından da yapılmıştır. Ancak bu tasniflemelerin büyük çoğunluğu birbiriyle benzerlik göstermekle birlikte derlenmiş olan dua ve beddua örneklerinin içeriğine ve yapısına bağlı olarak çeşitlenebilmektedir. Adıyaman ili ve çevresinden derlenen beddua (Kargış) örnekleri, anlamsal boyutu ve toplumda algılanış şekillerine göre üç başlık altında değerlendirilmiştir. Buna göre 220 beddua (kargış) örneği, 1. Sonucu Allah 'tan Dilenen Beddualar (Kargışlar), 2. Dilek ve Temenni Boyutunda Söylenen Beddualar (Kargışlar) ve 3. Deyimleşmiş Beddualar (Kargışlar), başlıkları altında değerlendirilmiş ve okuyucuya aktarılmıştır.

\subsubsection{Sonucu Allah'tan Dilenen Beddualar (Kargıșlar)}

$\mathrm{Bu}$ gurupta yer alan beddualar, insanların çaresizlik içinde kalmaları neticesinde sonucunu direk Allah'tan diledikleri istek ve temennilerdir. Bu beddualar aslen beddua hüviyetinden çıkıp; tamamen gerçekleşmesi için Allah'a yöneltilen dua mahiyetindedir. Özellikle Allah 'ından

21 Arzu Çiftçioğlu, "Bedduaların Anlam Açısından İncelenmesi", Lanet Kitabı, ed. Emine Gürsoy Naskali (İstanbul: Kitabevi Yayınları, 2009), 7-59.

22 Ersöz, “Türkiye Türkçesi Doğu Grubu Ağızlarında Bedduaların İşlevleri”, 34-42. 
bulan! Allah seni ıslah etsin! gibi örnekler, içinde bulunulan çaresizliği ortaya koymakta ve konuyu Allah'a havale etmektedir.

- Allah'indan bulan.

- Allah seni kahretsin.

- Allah iki yakanı bir araya getirmeye.

- Allah seni bildiği gibi ede.

- Allah seni getirmeye.

- Allah bedenini şirin etmeye.

- Sen beni çatlattın, Allah da seni çatlatsın.

- Allah seni islah etsin.

- Allah seni apara.

- Allah hakkından gelsin.

- Allah dirnağını uzatmaya.

- Allah seni dinlendirmesin.

- Allah yüzünü güldürmesin.

- Allah'ın hışmına uğrayan.

- Allah canını ala.

- Allah seni elimden ala.

- Allah seni getirmesin.

- Allah seni taş etsin.

- Sen bana çektirdin Allah da sana çektirsin.

- Allah senin kolunu kanadını kıra.

- Allah muradını gözünde koya.

\subsubsection{Dilek ve Temenni Boyutunda Söylenen Beddualar (Kargıșlar)}

Bu gurupta yer alan beddualar, tamamen karşıdaki kişiyi hedef alan ve bu kişinin ne şekilde acı çekmesini ya da nasıl bir sıkıntının içerisine düşmesini isteyen beddualardır. Ersöz'ün Tam Beddualar olarak ifade ettiği ve karşıdaki muhatabın önemsiz ya da sevilmeyen bir kişi olması durumunda söylenen beddua sözleridir. ${ }^{23}$ Çalışmada en kalabalık gurubu oluşturan bu örnekler, halen Adıyaman halkı içerisinde fazlaca kullanılmaktadır.

- Gözüne şiş çakıla.

- Soban tüte, damın damlaya, çocuğun ağlaya.

- Tike tike olan.

- Burçken budanan.

- Görkünü görmeyen.

- Bokun ağzından gele.

- Gafil kazalara rastlayan.

23 Ersöz, "Türkiye Türkçesi Doğu Grubu Ağızlarında Bedduaların İşlevleri”, 7. 
- Gençliğine doymayan.

- Felç, melemet olan.

- Ağma olan, elimde kalan.

- Dilenemez dilenci olan.

- Ekmek atli, sen yaya olan.

- Gündüz damdan kaçan.

- Kara yerin kahrı zemininde olan.

- Küçük mezar olan.

- Gün görmeyen, murad almayan.

- Bi sabunda bi suda giden.

- Tahtada saçın liflene.

- Bundan emdiğin kan, bundan emdiğin irin ola.

- Kucağın boş kala.

- Hanen harap ola.

- Gördüğün günde kalan.

- Başın bitten eteğin boktan kurtulmaya.

- Bir elin göre, diğeri görmeye.

- Karnın doymaya, yüzün gülmeye.

- İflah, berhüdar olmayan.

- Seninki de sana ede.

- Atın, itin bokunu yiyen.

- Üç evli olan, biri sağ eline, biri sol eline, diğeri de sakalına sıça.

- Evin ola, girip oturamayan.

- Kazanın kaynamaya, ocağın tütmeye.

- Yüzün nursuz, yemeğin tuzsuz ola.

- Haline itler güle.

- Gün görmeyen, devran sürmeyen.

- Devran sürmeyen.

- Dört adamın çiğninde (omzunda) gelen.

- Kuru sanci ola sana ha.

- Kuru sanciya yakalanan.

- Büyük daşın altında kalan.

- Kuş gibi uçan da kanadın kırıla.

- Bedenin yerde çürüye.

- Ocakta kalmayan.

- Ciyerin ağzından gele.

- Yanın yere gele.

- Yigidiken y1k1lan. 
- Ciyerin töküle.

- Farş malamat olan.

- Kör olan.

- Alın yeşilin üstüne töküle.

- Bölügin boğazına dolana.

- Daş olan.

- Tabutun bayraklara sarili gele.

- Yoğunan yoksan olan.

- Bayram başına karalı gele.

- Baban duvar dibinde kala.

- Gidişin ola dönüşün olmaya ha.

- Kurşunlara gide.

- Gözüne patlama düşe.

- Ettigin önüne gelsin.

- Kilidin belimde kala.

- Devrilen.

- Kanın içine aka.

- Mendil miraz almayan.

- Mirazın gözünde kala.

- Sen olan kansere tutulan.

- Sen olasın arabanın altında kalasın, parça pinçik olasın.

- Sen bir tekerin altında kalasin.

- Sen olasin kütükten silinesin.

- Sağlam gittin topal gelesin.

- Sen olasın kurşunlara dizilesin.

- Sen olan çift arvadın ola.

- Sen olan kara kazanlarda suyun kaynasin.

- Sen olan kör bir yılan seni isırsin.

- Giden de geri gelmeyen.

- Gözün ola avucumun içine düşe.

- Sürüm sürüm sürünesin.

- Arabanın altında kalasın, ölüm haberin bana gele.

- Etlerin töküle.

- Sen olan sirtüstü evden çıkasın.

- Sen olan bir hayır görmeyen.

- Gözün önüne düşe.

- Kör olan da kütük gezen.

- Anan öle. 
- Kan kusan.

- Gençliğinden ve evlatlarından hayır görmeyen.

- İki gözün çıka.

- Lap lap olan.

- Frengi çıka ha (Frengi: hastalık ismi).

- Domdom kurşununa gelen.

- Gün yüzü görmeyen.

- Behr-i bend olmayan.

- Yoğ olmayan.

- Kör olan da sürüm sürüm sürünen.

- Ekmek atli sen yayan olan.

- Parça pinçik olan.

- Yerre giren.

- Kara yerin dibine giren.

- K1zzil kurt.

- Nenen öle.

- Lallik olan.

- Kan içen de kan kusan.

- Sen olan da inim inim inleyen Ebzer Gaffar'da tekerin patlaya da aşağı loğlanan.

- Salacalara töküle.

- Kapın kuş bokuyla sıvana.

- Bazarlığın bazarda kala.

- Bokunlan oynayan.

- Kara yerin kahr-1 zeminine giresin.

- Anayın önüne serilen.

- Ak güne hasret kalasin.

- Ablan evde kala da sana sıçraya.

- Kamyonun altında kalan.

- Kara yerin zemini olan.

- Biriniz sabaha, biriniz akşama çıkmayan.

- Dert bulan, derman arayan bulamayan.

- Kiymalik et olan.

- Çocuk yüzü görmeyen.

- Oğlan işeği eteğine değmesin.

- Mezarında ters dönen.

- Etin lime lime ola.

- Ettiğini bulan.

- Boynun altında kala. 
- Yıkılmış duvarın altında kalasıca.

- Boyun devrilesice.

- Damina siçan tüneye.

- Canın içine akmaya.

- Paramparça olmayan.

- Ölü haberin gelmeye.

- Mezara sığmayan.

- Damdan düşen.

- Kara haberin gele.

- Sana top değe.

- Töremiyen.

- A ğzindan kan gele.

- Yanın yere gelmeyesice.

- Geberesice.

- Ekmek tavşan ola, sen kaplumbağa olan, kovalayan da yakalayamayan.

- Çoluk çocuğundan hayır görmeyen.

- Tez vakitte ettiğini bulan.

- Mezarında çelik-çomak oynayalar.

- Sen olan ki kendinden hayır görmeyen.

- Yaşın yerde sayila.

- Makinenin altında kalan.

- İki gözün avucuna düşe.

- Yediğin son ola.

- Yediğin ağzından gele.

- Kör-kütük olan.

- Yerişip de yetmeyen.

- Hanın harab ola.

- Hançer-pıçağın ağzına gelen.

- Meytin önüme gele.

- Ağzın yırtıla da ayağıma çarıh ola.

- Töremeyesice.

- Boyuna boy ipi ölçüle.

- Başını barğını yisin.

- Kanlı gömleğin önüme gele.

- Bedenine kurşun deye.

- Bedenine kurşun yağa.

- Datlı bişiren acı ola ha.

- Evin dinin yıhıla. 
- Evin dinin yıhılmaya.

- K1zzil-1 kurt-kuru sanc1.

- Ferc olan.

- Gözın kör ola.

- Gözıne dizıne dura.

- Iffleh-berhidar olmayan.

- İki gözın öyine aha.

- Rezzil malamat olan ha.

- Seninki de sana ede.

- Kalmiyasica.

- Kör olasica.

- Sen olan da pölük pölük olan.

- Sen olan da kapı kapı dilenen.

- Sabaha çıkmayan.

- Ocağın söne.

- Işı̆̆ın söne.

- Zibarasica.

- Kör-küt olan.

- Sağlam gittin topal gelesin.

- Sen olasin elime düşesin.

- Sen olasin kara kazanlarda yıkanasın.

- Ciyerinden kan damlaya.

- Amansiz derde yakalanan.

- Oğlan beşiğini sallayamayasın.

- Eliniz birbirine kavuşmaya (Nişanlılar için söylenir).

- Başın karnın bir ola (Hamileler için söylenir).

- Parçalanasın, küçük parçan kulağın kadar ola.

- Burcu ham budanan (Gençken ölesin).

- Arap Aziz gibi olanız (On iki kardeşten biri olan Arap Aziz, kardeşleriyle sofrada yemek yerken, sofraya bir hayvan düşer ve o hayvan yemeğe karışır. Bu yemekten yiyen on iki kardeş zehirlenerek ölür).

- Bozo gil gibi olanız (İki kardeş birbirini vurur, bu kardeşlerden birinin ismi Bozo'dur).

- Firek talasin (Yara senin her tarafina yayılsın).

- Çöçün olasın (Ferc olasın).

- Kara kanser olan.

- Zikkımın kökünü yiyen.

- Zehir-zıkkım olsun.

- Senin evladin da sana ede. 
- Gördügüün gün bu ola.

- Gittiğin yerde dinlenmiyen.

- Sen olan dert yiyen, zıkkım yiyen.

- Hiş olan.

- Sen olan kapı kapı dolaşan, ekmek bulamıyan.

- Sen olan mezarında yatamiyan.

- Mezara yan gelesin.

- Geberen de geberen.

- Kucağına kundak görmeyesin.

- Evlat hasretiyle yanasin.

- Kafana dam loğu düşe.

- Tankerin altında kalan.

- Karnına kan düşe.

- Oğlan yüzüne hasret olan.

- Evlat yüzüne hasret olan.

- Sen bi yana düşen, çocuğun bi yana düşe (Hamilelere söylenir).

- Bu göğsümden emdiğiniz kan, bu göğsümden emdiğiniz irin olsun (Evlada söylenir).

- Her tiken bir dağın başında kala.

- Bokunu duvara çarpan.

- Ayağa kalkamiyan.

- Çoluğun çocuğun elinin altına düşen ama sana kimse bakmıya.

- Malından mülkünden hayır görmiyen.

- Köpeklere lime lime olan.

- Pisliğini duvara çarpan.

- Sen sen olan, ağzın yüzün yamula.

- A Ăgin yirtıla.

- Derde tutulan.

- Gözü akasıca.

- Ferc olan da ele ayağa düşen.

- Karninla burnunla giden (Hamilelere söylenir).

- Mirazsiz giden.

- Ne alan, ne veren.

- Bir elin göre, bir elin görmiye.

- Sen bana gün göstermedin, sen de gün görmiyesin.

\subsubsection{Deyimleşmiş Beddualar (Kargıșlar)}

- Allah'indan bulan.

- Allah seni kahretsin. 
- Allah iki yakanı bir araya getirmeye.

- Allah seni islah etsin.

- Allah'indan bulan.

- Yanın yere gele.

- Gidişin ola dönüşün olmaya ha.

- Sen olasin kurşunlara dizilesin.

- Sürüm sürüm sürünesin.

- Yoğ olmayan.

- Boyun posun devrilen.

- Ettiğini bulan.

- Boynun altında kala.

- Boyun devrilesice.

- Gözın kör ola.

- Gözıne dizine dura.

- Rezzil malamat olan ha.

- Zıkkımın kökünü yiyen.

- Zehir-zıkkım olsun.

- Sen bana gün göstermedin, sen de gün görmiyesin.

- El diline düşen.

- Burnundan fitil fitil gele.

- Dermansiz derde düşen.

- İnim inim inleyesin.

- Sizim sizim sizlanan.

- Boyun posun devrile.

\section{Sonuç}

İnsanlık tarihi kadar geçmişe götürülebilecek alkış ve kargışlar, her coğrafyada, her toplumda, bazen bilinçli bazen de bilinçsiz olarak insanların ağzından dökülen ve sözlü anlatımın en geniş yelpazesini oluşturan anlatım türlerinden birisidir. Birçok çalışmada atasözleri ve deyimler ile birlikte kalıp sözler gurubunda değerlendirilseler de bu türlerden, yöresel özelliklerinin fazla olmasından dolayı ayrılmaktadırlar. Bu farklılık, alkış ve kargışların yöresel olarak derlenip toparlanmalarını ve kayıt altına alınarak, gelecek kuşaklara aktarılmasını zorunlu hale getirmektedir.

Çalışmada, 109 dua (Alkış), 257 beddua (Kargış), örneği çalışmaya dâhil edildi ve bu örnekler kendi içerisinde anlamsal ve yöneltilen kişiye bağlı olarak tasniflenmeye çalışıldı. Özellikle alkışların tamamen Allah’tan dilenmesi ve O'na yönelik söylenmesi, kargışların ise muhatabını esas alan bir yoğunlukta ortaya çıkması en belirgin özellik olarak dikkatleri çekmektedir. Dil özellikleri bağlamında değerlendirildiğinde, Adıyaman alkış ve kargışları, 
içeriğinde fazlaca yöresel ağız özelliklerine yer vermesi ile halk kültürü çalışmacılarının olduğu kadar dilbilimcilerin de dikkatini çekeceği muhtemeldir. Hem dua hem de beddua örnekleri içerisinde toplumun her kesimini muhatap alan ve herkes tarafindan benimsenerek, deyimleşmiş hale dönüşen örneklerin bulunması ve bu örneklerin artık yöresel mahiyetten çıkarak bütün bir coğrafyada kullanılıyor olması, alkış ve kargışların evrensel metinler içerisinde de değerlendirilmesi gerekliliğini ortaya koymaktadır.

\section{Kaynak Şahıslar}

$\begin{array}{lllll}\text { Ahmet Çoban } & \text { Lise } & \text { Yaş: } 52 & \text { Memur } & \text { Adıyaman. } \\ \text { Ali Kırmızı } & \text { Lise } & \text { Yaş: } 72 & \text { Ormanıı } & \text { Adıyaman. } \\ \text { Aydın Güler } & \text { Yüksekokul } & \text { Yaş: } 44 & \text { Memur } & \text { Adıyaman. } \\ \text { Bedriye Tektaş } & \text { İlkokul } & \text { Yaş: } 43 & \text { Ev Hanımı } & \text { Adıyaman. } \\ \text { Cebrail Demir } & \text { Lise } & \text { Yaş: } 41 & \text { Esnaf } & \text { Adıyaman. } \\ \text { Emine Özkalaycı } & \text { Okumaz-Yazmaz } & \text { Yaş: } 56 & \text { Ev Hanımı } & \text { Adıyaman. } \\ \text { Ferhat Yılboğa } & \text { Lise } & \text { Yaş: } 29 & \text { Memur } & \text { Adıyaman. } \\ \text { Hamit Özer } & \text { Üniversite } & \text { Yaş: } 56 & \text { Terzi } & \text { Adıyaman. } \\ \text { Hatice Bağışlar } & \text { Lise } & \text { Yaş: } 34 & \text { Ev Hanımı } & \text { Adıyaman. } \\ \text { Haydar Demir } & \text { İlkokul } & \text { Yaş: } 68 & \text { Çiftçi } & \text { Adıyaman. } \\ \text { H. Reşit Beli } & \text { Yüksekokul } & \text { Yaş: } 44 & \text { Memur } & \text { Adıyaman. } \\ \text { I. Nebi Akçıl } & \text { Ortaokul } & \text { Yaş: } 48 & \text { Gazeteci } & \text { Adıyaman. } \\ \text { Mahmut Bereket } & \text { Lise } & \text { Yaş: } 45 & \text { Esnaf } & \text { Adıyaman. } \\ \text { Mine Atal } & \text { Okumaz-Yazmaz } & \text { Yaş: } 48 & \text { Ev Hanımı } & \text { Adıyaman. } \\ \text { Saadet Karakaş } & \text { İlkokul } & \text { Yaş: } 63 & \text { Ev Hanımı } & \text { Adıyaman. } \\ \text { Zahide Dura } & \text { Okumaz-Yazmaz } & \text { Yaş: } 70 & \text { Ev Hanımı } & \text { Adıyaman. } \\ \text { Zahide Sitil } & \text { İlkokul } & \text { Yaş: } 63 & \text { Ev Hanımı } & \text { Adıyaman. } \\ \text { Zehra Şahinalp } & \text { Üniversite } & \text { Yaş: } 27 & \text { Öğretmen } & \text { Adıyaman. } \\ \text { Zeynep Bozkurt } & \text { Okumaz- Yazmaz } & \text { Yaş: } 77 & \text { Ev Hanımı } & \text { Adıyaman. }\end{array}$

\section{Kaynaklar}

Akalın, L. Sami. Türk Dilek Sözlerinden Alkışlar Karglşlar. Ankara: Kültür Bakanlığı Halk Kültürünü Araştırma Dairesi Yayınları, 1990.

Beydili, Celal. Türk Mitolojisi Ansiklopedik Sözlük. Çeviren Eren Ercan. Ankara: Yurt Yayınları, 2005.

Boratav, Pertev Naili. Türk Halk Bilimi I-100 Soruda Türk Halk Edebiyatı. İstanbul: Gerçek Yayınevi, 1995.

Bulut, Serdar. “Anadolu Ağızlarında Dini İnançları Yansıtan Kalıp Sözler”, The Journal Of Academic Social Science Studies (JASSS) 6/1 (2013): 435-465.

Bulut, Serdar. "Türkiye Türkçesi Ağızları İle Kıbrıs Türk Ağızlarında Ortak Kullanılan Kalıp Sözlerden HayırDualar ve Beddualar”, Akademik Sosyal Araştırmalar Dergisi (ASOS JOURNAL) 4/24 (2016): 298-308.

Çiftçioğlu, Arzu. "Bedduaların Anlam Açısından İncelenmesi", Lanet Kitabı, 7-59, Editör Emine Gürsoy Naskali. İstanbul: Kitabevi Yayınları, 2009.

Çobanoğlu, Özkul ve Sacide Çobanoğlu. "Türk Halk Kültüründe Konuşmalık Türler Bağlamında Sözel

Nasihatler, Dua ve Beddualar”, Avrasya Uluslararası Araştırmalar Dergisi 4/7 (2015): 1-32.

Duymaz, Ali. "Sihir Şiirlerinin Bir Türü Olarak Alkışlar”, Milli Folklor, 45 (2012): 15-21. 
Elçin, Şükrü. Halk Edebiyatına Giriş. Ankara: Akçağ Yayınları, 2004.

Ergin, Muharrem. Dede Korkut Kitabı. Ankara: Türk Dil Kurumu Yayınları, 2004.

Ersöz, Serpil. “Türkiye Türkçesi Doğu Grubu Ağızlarında Bedduaların İşlevleri”, Türk Dünyası İncelemeleri Dergisi XIV/2 (2014): 29-46.

Harmanc1, Meriç. "Dede Korkut Hikâyelerindeki Alkış ve Kargışlara İşlevsel Bir Yaklaşım”, Kocaeli Üniversitesi Sosyal Bilimler Enstitüsü Dergisi 23 (2012): 1-17.

Kaya, Doğan. "Dualar ve Beddualar”, Türklük Bilimi Araştırmaları Dergisi 4 (1997): 99-121.

Kaya, Doğan. Türk Halk Edebiyatı Terimleri Sözlüğü. Ankara: Akçağ Yayınları, 2007.

Terzioğlu, Öykü. “Alkış ve Kargışların Sözlü Kültürdeki Yerleşik Kodların Aktarımını ve Yeniden Üretimini Kolaylaştıran Biçimsel Özellikleri”, Milli Folklor 75 (2007): 34-37. 
